\title{
REFLEXOS DA INSTITUCIONALIZAÇÃO DA ENFERMAGEM NO INTERIOR DOS HOSPITAIS: ATUAÇÃO DAS IRMÃS DE JESUS NA SANTÍSSIMA EUCARISTIA NA SANTA CASA DE CACHOEIRO DE ITAPEMIRIM (1929 - 1950)
}

\author{
REFLECTIONS ON THE INSTITUTIONALIZATION OF NURSING \\ WITHIN THE HOSPITALS: THE SISTERS OF JESUS PERFORMED \\ IN THE HOLY EUCHARIST AT SANTA CASA DE CACHOEIRO DE \\ ITAPEMIRIM (1929 - 1950)
}

Luciene Carla Corrêa Francelino ${ }^{1}$

RESUMO: O presente artigo tem como objeto de análise a atuação das Irmãs de Jesus na Santíssima Eucaristia na Santa Casa de Misericórdia de Cachoeiro de Itapemirim, entre os anos de 1929 a 1950. O recorte temporal se justifica pelo período em que as freiras administraram internamente o hospital. A hipótese defendida é que as religiosas cuidavam dos doentes internados na instituição, mas esse cuidado rompia as fronteiras do corpo e alcançava os limites da alma, visto que estas se preocupavam com o conforto espiritual dos convalescentes e de seus familiares, favorecendo a cura ou minimizando o sofrimento e possibilitando uma melhoria na qualidade de vida daqueles que eram atendidos no hospital. A pesquisa visa analisar como as mudanças causadas pela institucionalização da enfermagem chegaram ao município e de que maneira estas repercutiram no dia a dia da instituição.

Palavras-Chave: Religiosas; Santa Casa; Cachoeiro de Itapemirim.

ABSTRACT: The purpose of this article is to analyze the performance of the sisters of Jesus in the Holy Eucharist in the Holy House of Mercy of Cachoeiro de Itapemirim between the years of 1929 and 1950 . The temporal cut is justified by the period in which the nuns administered the hospital internally. The hypothesis defended is that the religious cared for the patients hospitalized in the institution, but this care broke the boundaries of the body and reached the limits of the soul, since they were concerned with the spiritual comfort of the convalescent and their relatives, favoring healing or minimizing the suffering and enabling an improvement in the quality of life of those who were treated in the hospital. The research aims to analyze how the changes caused by the institutionalization of nursing came to the municipality and how they impacted on the day to day of the institution.

Keywords: Religious; Holy House; Cachoeiro de Itapemirim.

1 Universidade Federal do Espírito Santo (UFES) Mestranda do Programa de Pós-Graduação em História Social das Relações Políticas 


\section{INTRODUÇÃO}

A pesquisa tem como objeto de análise a atuação das religiosas da congregação de Jesus na Santíssima Eucaristia, no interior da Santa Casa de Misericórdia de Cachoeiro de Itapemirim - município localizado no sul do estado do Espírito Santo - entre os anos de 1929 a 1950. A escolha do período deve-se ao momento em que as freiras passam a administrar vários setores da instituiçáo, à exemplo: centro cirúrgico, maternidade, lavanderia, cozinha e rouparia. Embora não possuíssem conhecimentos técnicos sobre enfermagem, atuavam como tais, no cotidiano do nosocômio. A data que finaliza a pesquisa é referente ao momento em que as religiosas deixam de administrar o hospital.

Um estudo sobre a atuação das religiosas da congregação de Jesus na Santíssima Eucaristia, junto aos doentes da Santa Casa de Cachoeiro justifica-se por várias razóes. Primeiramente esse tema é relevante na medida em que o número de trabalhos acerca da saúde no município ainda é muito escasso. A maioria dos estudos envolvendo a temática e principalmente sobre a Santa Casa demonstram ter como principal objetivo enaltecer a instituição ou pessoas que de alguma forma se destacaram no exercício de sua profissão junto ao hospital. Em segundo lugar, estudar a atuação das religiosas nesse período é analisar a condição feminina na sociedade patriarcal da época. Demonstrando que a clausura muitas vezes era uma forma de resistência, um meio de burlar a predestinação ao casamento e confinamento à esfera doméstica. Enquanto a atuação no hospital, podia, entre outras coisas, representar espaços de liberdade, no qual tais mulheres trabalhavam e controlavam a rotina hospitalar, através dos horários das refeiçóes, medicamentos ministrados aos pacientes, além de supervisionarem o trabalho dos demais funcionários.

A pesquisa foi realizada com a finalidade de verificar as açóes filantrópicas prestadas pela Santa Casa de Cachoeiro aos desvalidos e necessitados, bem como a importância dessas medidas junto aos assistidos. Em relação à atuação das religiosas procuramos demonstrar em que medida a sua presença influenciou na opinião que a coletividade possuía do hospital. Outro fator importante foi analisar a transição do conceito de cuidar para o curar a partir da institucionalização da enfermagem e das novas medidas profiláticas instituídas pelos institutos de saúde pública a partir do final da década de 1930 .

A hipótese defendida nesse trabalho é que antes da chegada das irmãs na Santa Casa, poucas pessoas procuravam o auxílio do hospital, em virtude de que os mais abastados estavam acostumados com o médico de família, enquanto a grande maioria da população buscava a cura de várias moléstias, junto aos que praticavam a medicina alternativa, como curandeiros e práticos. Havia um consenso entre a populaçáo de que o hospital era para auxílio de indigentes, assim apenas estes ou os casos extremos deveriam buscar atendimento no nosocômio. A partir da presença das religiosas muitas mulheres passaram a buscar atendimento junto ao mesmo, além de levarem seus filhos para serem atendidos, quando necessário. Além disso os pacientes e seus familiares passaram a desfrutar de um tratamento que rompia as fronteiras do corpo e alcançava os limites da alma, na medida em que as freiras se preocupavam com o conforto espiritual destes, o que certamente favorecia o tratamento, minimizando o sofrimento, tão comum em situações de fragilidade e enfermidade. 
Partindo da análise de uma documentaçáo variada produzida pela Santa Casa de Cachoeiro, como: livro de atas da diretoria, livros de atas do conselho diretor, livro de contratação de funcionários, além de Estatuto de funcionamento do hospital e Regimento Interno, foi traçado um perfil da instituição, bem como da dinâmica de funcionamento da mesma.

Em relação à congregaçáo de Jesus na Santíssima Eucaristia e à dinâmica interna da mesma, foram analisadas cartas e circulares escritas por madre Gertrudes de São José, ${ }^{2}$ entre os anos de 1927 até 1957 às religiosas da Santa Casa e demais freiras que atuavam em outras obras sociais. Grande parte da história dessas irmás será contada a partir da análise das cartas pessoais e circulares escritas pela Superiora da congregação, mas também a partir de um olhar sensível sobre a história das mulheres e sua condição, até o segundo quartel do século XX.

A pesquisa utilizou relevantes contribuições dos jornais $O$ Cachoeirano - fundado em 1877 - e Correio do Sul — fundado em 1928. Ambos foram, a seu tempo, os arautos da sociedade cachoeirense, noticiando diariamente atos oficiais do poder público, das associaçóes e entidades que atuavam no município. Ambos contribuíram de forma significativa para elucidar questôes pertinentes à pesquisa, para as quais as respostas não foram encontradas na vasta documentaçáo analisada nos acervos da Santa Casa, visto que parte da documentaçáo se perdeu com o tempo.

\section{A FUNDAÇÃO DOS HOSPITAIS AO LONGO DA HISTÓRIA}

Desde a antiguidade a assistência aos desvalidos, pobres e doentes esteve associada à filantropia e caridade, seja através de açôes implementadas pela igreja católica e seus membros ou pelo trabalho de leigos. A palavra hospital é originária de hospitalidade e hotel, sendo que a Europa medieval à partir do século IV presenciou o surgimento de estabelecimentos religiosos que serviam como lugar de refúgio para necessitados e peregrinos, esses primeiros estabelecimentos eram mantidos por ordens religiosas, mas apesar de conter várias camas e até aparatos para a assistência aos desvalidos, esses locais podiam ser adaptados de acordo com a necessidade, não tendo portanto, um caráter de permanência (BYNUN, 2011).

Os doentes foram acolhidos em mosteiros e conventos até o século IX, quando a igreja católica, através de um concílio no ano 816 , estabeleceu a obrigatoriedade de construção de hospitais - de caráter permanentes - nesses locais. Mas a partir do século XII com o enfraquecimento das relaçóes feudais e a migração para as cidades, várias epidemias - em especial de peste bubônica - assolaram a população europeia, acarretando uma demanda crescente por hospitais. Nessas instituiçôes passaram a atuar religiosos e leigos, estabelecendo um cuidado junto aos enfermos, muito próximo do que futuramente seria inaugurado pela enfermagem moderna. 
Em um contexto de epidemias, fome e guerras, surge a Misericórdia de Portugal, criada em 1498 sob o patrocínio de D. Leonor e confirmada por seu irmão, o rei D. Manuel I, tendo como principal objetivo proporcionar auxílio espiritual e material aos necessitados através da assistência institucionalizada aos doentes, tornando-se, portanto, um modelo para a fundação de diversos hospitais.

O modelo assistencial da Santa Casa chegou ao Brasil, assim como nas demais colônias portuguesas, a partir do século XVI, sendo que a fundação destas favoreciam tanto a metrópole, quanto os setores mais abastados dos locais em que estas eram instaladas. Ou seja, para a Coroa portuguesa o estabelecimento de Santas Casas náo era oneroso do ponto de vista financeiro à medida que seus custos eram pagos pelos "endinheirados" de cada localidade, por outro lado os beneméritos que financiavam a instalaçáo de tão importante instituição eram privilegiados do ponto de vista simbólico, tendo prestígio e notoriedade em suas localidades, favorecendo muitas vezes a inserção na vida política ou na "alta sociedade".

As Santas Casas mais expressivas, principalmente a partir do século XVIII administravam além de serviços hospitalares, recolhimento de órfấos, boticas, roda dos enjeitados, cemitérios, visitavam cadeias, auxiliavam na alimentaçáo e no livramento de presos pobres e distribuíam esmolas. Na América portuguesa dois exemplos que mais se aproximaram desse tipo de atuação foram as Misericórdias do Rio de Janeiro e de Salvador (FRANCO, 2011).

A fundação das primeiras Santas Casas em território brasileiro acompanhou o surgimento de vilas e povoados, concedendo à instalação dessas novas instituiçóes um duplo papel: em primeiro lugar confirmava a instituição como uma das principais confrarias em tempos imperiais e em segundo, a presença de uma irmandade como a Santa Casa conferia uma identidade — mesmo que lusa — às frágeis povoaçóes que tanto careciam de elementos e instituiçóes que as distinguisse e com as quais se identificassem. Em 1584, o então jesuíta José de Anchieta, relata com entusiasmo a estruturação da assistência aos necessitados na colônia:

Em todas as capitanias há Casas de Misericórdia, que servem de hospitais [...] em que se dão esmolas, assim em vida como em morte e se casam muitas órfã́s, curam enfermos de toda a sorte e fazem outras obras pias conforme o seu instinto e possibilidade de cada uma e anda o regimento delas nos principais da terra (JOSÉ DE ANCHIETA, 1933, p. 321).

As capitanias de Pernambuco e São Vicente disputam o título de ter abrigado a primeira Misericórdia em terras brasileiras, Olinda (1539? 1545) e Santos (1543), porém muitos historiadores como Francisco Adolfo Varnhagem e Serafim Leite concordam que essa premissa é privilégio da irmandade de Santos, fundada por Brás Cubas em 1543 e confirmada por alvará real no mês de abril de 1551. Geralmente a fundaçáo de uma Misericórdia ocorria concomitantemente à criação de uma cidade. Nos anos seguintes foram instituídas confrarias em outros locais como no Espírito Santo (1545), Bahia (1549), São Paulo (1560) e Ilhéus (1564). A Casa de Misericórdia da Bahia praticava a filantropia social mantendo um hospital, uma casa de retiros, além da "roda dos expostos" para 
recém-nascidos rejeitados por suas famílias. O Recolhimento ou casa de retiro acolhia jovens de família, em idade de casamento, caso estas estivessem com a sua honra ameaçada, pela perda do pai, da mãe ou de ambos. Também acolhia viúvas e solteiras de boa reputação ${ }^{3}$ mediante um pagamento. Esse recolhimento também poderia ser utilizado como uma espécie de abrigo provisório, para as órfãs de Portugal, conforme o texto:

O ano seguinte de 1551 - narra Frei Vicente — mandou el-rei outra armada, e por capitão dela Antônio de Oliveira Carvalhal para alcaide-mor de Vila Velha, com muitas donzelas da Rainha D. Catarina e do mosteiro das órfâs, encarregadas ao governador para que as casasse, como o fêz, com homens a quem deu ofícios da república e algumas dotou de sua própria fazenda" (CALMON, 1971, p. 233).

A "roda dos expostos" — também conhecida como roda dos enjeitados — era comum em muitas Misericórdias, geralmente ficavam junto ao muro das Santas Casas, sendo metade da roda para o interior e a outra metade para o exterior, desse modo a identidade da pessoa que ali abandona a criança, ficava resguardada. Essas crianças eram geralmente filhos de mães solteiras, que eram ali deixadas na calada da noite, para que fossem adotadas por famílias de posses ou abrigadas em algum orfanato da cidade (MOULIN, 2011).

\section{SANTA CASA DE MISERICÓRDIA DE CACHOEIRO DE ITAPEMIRIM}

Em Cachoeiro de Itapemirim a Santa Casa de Misericórdia foi fundada em 27 de janeiro de 1900 e inaugurada no dia 11 de fevereiro do mesmo ano. Sendo que esta originou-se da Associação Beneficência Cachoeirense, criada em 25 de dezembro de 1889.

Vale destacar que esta Associação que deu origem a Santa Casa, era composta majoritariamente por membros da maçonaria — dos 53 fundadores, 36 eram maçons — náo tendo na época vinculação estreita com a Igreja Católica, como aconteceu com a maioria das confrarias responsáveis pela instalação de Santas Casas em território brasileiro. As demais Santas Casas fundadas por irmandades tinham como principal documento regulador de suas funçôes o Compromisso, ${ }^{4}$ sendo seus membros denominados de irmãos, em contrapartida a Misericórdia de Cachoeiro - certamente por influência da maçonaria - era regida por um Estatuto, sendo os membros chamados de sócios. Outro elemento de diferenciação é que em vez de um provedor, a Santa Casa de Cachoeiro possuía um presidente.

Segundo Foucault (1977, p. 76), “o século XX falará obstinadamente da morte não para supervaloriza-la com temor, mas para corrigir seu curso, através de intervençóes públicas, impedindo a propagação de moléstias e o enfraquecimento das populaçôes”. A figura do médico começou a ganhar destaque no século XIX, alcançando a condição de cientista formado por universidades e, patrocinado pelo Estado, contudo isso não acontece

3 Ser uma mulher de boa reputação na época, significava ser uma mulher recatada, presumidamente virgem, que não havia se envolvido em relacionamento amoroso capaz de comprometer a sua honra. Ela deveria respeitar os rígidos padrões patriarcais vigentes na época.

4

Principal documento que regia o funcionamento das Santas Casas. 
de uma hora para outra, foi longo o caminho percorrido. O número de médicos, assim como na atualidade, era insuficiente para atender à população do vasto território brasileiro, além disso grande parte da populaçáo estava acostumada a utilizar os conhecimentos da medicina alternativa, representada pelo saber popular de parteiras, práticos, rezadeiras e até farmacêuticos. Entretanto, aqueles que possuíam a "licença para curar" passaram a combater com veemência tais profissionais, chamando-os inclusive de charlatães. Para rechaçar tais profissionais e legitimar a profissão, os médicos passaram a popularizar os conhecimentos científicos através de sessóes em jornais, atendimento a populares em consultórios improvisados, além da realização de procedimentos médicos especializados. Em Cachoeiro, quando ainda não havia um hospital, que atendesse a situaçôes de emergência, foi realizada uma amputação na altura do antebraço direito de um homem residente em Muqui, vítima de explosão por dinamite. $\mathrm{O}$ mesmo foi operado pelo médico Raulino de Oliveira, tendo como assistentes um farmacêutico e um cirurgiáo dentista, o fato foi noticiado no jornal O Cachoeirano 5 — de 01 de junho de 1894.

Uma das principais consequências do incentivo à caridade para os desvalidos, no campo da medicina, foi a disseminação de hospitais filantrópicos, maternidades e sanatórios patrocinados pela iniciativa privada. Em ata da terceira sessão Ordinária da Câmara municipal de Cachoeiro de Itapemirim em 10 de junho de 1896 foi decidido o seguinte:

[...] considerando que o $\$ 1 .^{\circ}$ do artigo 36 da lei n. 6 atribue ao governo municipal a competência de crear casa de caridade, inspencionar as existentes e fiscalizar o seu regime. Considerando que neste município particulares levantara $\mathrm{m}$ a ideia da creação de um hospital de caridade [...] considerando que a iniciativa individual pode ser mais proveitosa que a direta acção do governo: propomos que o governo municipal faça entrega a Associaçáo ou Irmandade que se organizar do saldo existente e da casa adquirida, desde que a Associaçáo ou Irmandade apresente os seus estatutos devidamente aprovados. (Acta da 3. a sessão Ordinária da Câmara Municipal de Cachoeiro de Itapemirim, 10/06/1896).

Composta por médicos e membros da sociedade cachoeirense a Associação Beneficência fundou um hospital destinado ao atendimento de pessoas pobres e desvalidas que viviam no município, bem como em todo o sul do estado do Espírito Santo. No dia da inauguração, toda a populaçáo foi convidada a comparecer, sendo os comerciantes instruídos que fechassem os seus comércios a fim de prestigiarem táo importante acontecimento:

\footnotetext{
No sábado, dia 27 do corrente, terá lugar a inauguração do hospital fundado às expensas da caridade pública [...] tendo a comissão recebido a delegação do povo e querendo dar o caráter festivo, a quem tem direito factos desta ordem, tem a honra de convidar às Exmas. famílias em participar e ao povo em geral para comparecerem na casa situada à Tijuca e já conhecida por Hospital, pela 1 hora da tarde, afim de proceder-se a necessária inauguração [...] roga-se aos Srs comerciantes o obsequio de fecharem suas portas do meio dia em diante, afim de que possão todos tomar parte na referida festa (O Cachoeirano, 23 de janeiro de 1900).
}

O hospital fundado a partir da caridade e beneficência dos moradores do município de Cachoeiro de Itapemirim, confirmava em seu Estatuto através do Artigo II seu caráter de assistência aos desvalidos e necessitados:

$5 \quad$ Jornal em circulação no município de Cachoeiro de Itapemirim desde 1877. 
São fins da Santa Casa de Misericórdia de Cachoeiro de Itapemirim: I - continuar a manter a assistência hospitalar das pessoas indigentes; II - manter um consultório médico para pessoas pobres; III- fornecer gratuitamente aos indigentes não internados no seu hospital, os medicamentos receitados pelo médico da Santa Casa; [...] VII - fazer gratuitamente o enterro dos indigentes que falecerem no hospital (Estatutos da Santa Casa de Misericórdia de Cachoeiro de Itapemirim, 1919).

O Hospital recebia auxílio através de quermesses e doação da bilheteria de espetáculos circenses e de outros artistas que estivessem se apresentando na cidade. No dia 5 de setembro de 1901 o jornal $O$ Cachoeirano noticia a realização de uma quermesse em benefício do hospital, destacando que o Sr. Alberto Ferreira "um verdadeiro coração aberto a todos os actos de filantropia” obteve dos Srs. Agricultores da zona da Valla do Souza, diversas sacas de café, destinadas ao mesmo fim humanitário. Nesta mesma nota a Associação de Beneficência Cachoeirense afirma ter recebido a quantia de $220 \$ 700$ (duzentos e vinte mil e setecentos réis) de um espetáculo circense realizado no dia 8 de agosto em favor da instituiçãao, tendo ainda a receber a quantia de $13 \$ 000$ (treze mil réis).

Assim como ocorreu durante a colonização do Brasil, em que as Misericórdias possuíam um aspecto semi-burocrático, atuando junto à população com medidas que na verdade eram de responsabilidade do poder público, a Misericórdia do sul do estado do Espírito Santo, recebia subvenção municipal e estadual, encarregando-se da assistência aos indigentes, pobres, desvalidos e doentes, conforme nota publicada no jornal $O$ Cachoeirano em 22 de março de 1900, afirmando que a presidência do Estado concederia mensalmente ao hospital a importância correspondente ao auxílio anual de 4:000\$ (quatro mil réis) em conformidade com a lei n. ${ }^{\circ} 339$ de 16 de novembro de 1899.

O hospital era popularmente conhecido pelo cognome: Hospital de Caridade - um termo genérico utilizado na época para fazer referência a hospitais filantrópicos — ou hospital da Associaçáo de Beneficência, como constava na maioria da documentaçáo do nosocômio até 1920. Na imprensa local o termo Santa Casa começa a aparecer com mais frequência a partir de 1913, mas concomitantemente ou relacionando-se a Associação Beneficência Cachoeirense. Isso dificulta a pesquisa dos historiadores iniciantes, que ávidos por documentação referente à Santa Casa deixam passar despercebidos registros com denominações díspares.

No ano de 1919 ocorreu a reforma do Estatuto que regia o hospital desde a sua fundação, sendo noticiado no jornal O Cachoeirano do dia 14 de novembro de 1919, a convocação dos sócios para uma reunião extraordinária cujo objetivo era aprovar um novo Estatuto - o projeto foi apresentado na íntegra juntamente com a nota de convocação para conhecimento e análise preliminar dos sócios - pois segundo o informe, o que estava em vigor na época, "não correspondia ao atual desenvolvimento da Santa Casa". No capítulo primeiro do novo Estatuto foi determinada a retirada do termo Associação de Beneficência e a introdução permanente do título Santa Casa: 


\section{CAPÍTULO I}

Denominaçôes e fins,

Art. 1 - A Associação fundada nesta cidade sob a denominação de ASSOCIAÇÃO DE BENEFICENNCIA CACHOEIRENSE passa a denominar-se: SANTA CASA DE MISERICÓRDIA DE CACHOEIRO DE ITAPEMIRIM (Jornal O Cachoeirano, 14 de novembro de 1919).

Essa mudança passou a constar nos registros oficiais da instituição, sendo que a partir de janeiro de 1920 não aparece mais nos documentos do hospital referências à Associação de Beneficência. $\mathrm{Na}$ ata de sessão extraordinária do dia 22 de agosto de 1921 foi descrito o nome Santa Casa cinco vezes, levando em conta ser o documento da própria instituição seria desnecessário empregar os termos: "o presidente da Santa Casa" — utilizado repetidamente três vezes — "a diretoria da Santa Casa" e ainda, "possuindo a Santa Casa". Ao que tudo indica, utilizar reiteradamente a designação da instituição neste caso, tinha por objetivo asseverar a mudança definitiva de nomenclatura do nosocômio.

Em entrevista gravada no ano de 1990 no Centro de Estudos da Santa Casa pelo médico Dr. Sérgio Damião, em virtude da comemoração dos noventa anos de fundação do hospital, o entrevistado, Dr. Dalton Penedo - médico que ingressou na instituição na década de 1930 - informou que as pessoas que utilizavam os serviços do hospital nesse período eram pertencentes às camadas menos favorecidas da população, indivíduos vítimas de acidentes ou em tratamento de moléstias graves. As pessoas mais abastadas tinham o médico de família, que realizava atendimento domiciliar. Havia ainda um sem número de práticos e curandeiros que realizavam a chamada medicina alternativa, ou seja, havia uma certa resistência por parte da coletividade em procurar o hospital. Mas esse cenário começou a mudar a partir da chegada das freiras que passaram a atuar na Santa Casa em 1929. Outro fator importante para alterar esse quadro foi a divulgação dos avanços da medicina e das novas práticas profiláticas nos jornais do município, através de folhetins e sessóes que tinham a finalidade de informar sobre os sintomas de diversas doenças bem como formas de prevenção e tratamento, sempre utilizando uma linguagem prática e acessível a todos (figura 1).

Figura 1 - Jornal 0 Correio do Sul

18 de abril de 1929, informando sobre o combate ao mosquito transmissor da febre amarela

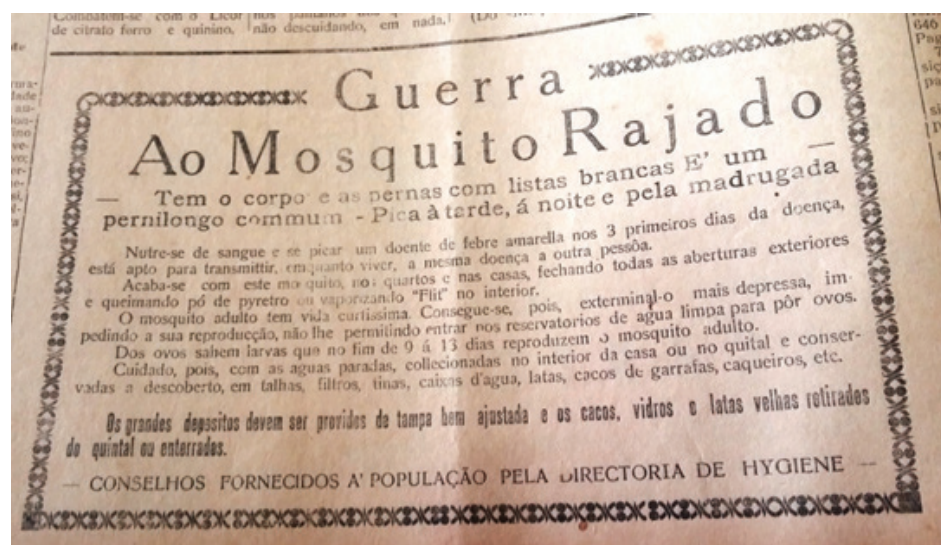

Fonte: Acervo pessoal da autora 


\section{RELIGIOSAS NO INTERIOR DOS HOSPITAIS - AS IRMÃS ENFERMEIRAS}

O trabalho junto aos doentes foi uma das várias formas de atuação filantrópicas que ao longo dos séculos aliou-se à história da enfermagem. Várias ordens religiosas foram criadas voltadas para a assistência aos desvalidos, esses ideais de amor ao próximo, marcaram o desenvolvimento da enfermagem, estabelecendo um modelo comportamental para o cuidado com os enfermos. Na primeira era cristá — até o ano 500 — uma das primeiras ordens oficiais de mulheres que trabalhavam junto aos desvalidos foram as diaconisas e as viúvas, mais tarde integraram-se as virgens, as presbiterianas - integrantes dos presbitérios —, as canônicas e as irmãs de caridade (DONAHUE, 1993).

A companhia das Irmãs de Caridade foi fundada em 1633 na França, pelo padre Vicente de Paula e pela religiosa Luísa de Marillac. O momento em que essa ordem foi criada coincide com o período em que a miséria e as doenças causadas por longos anos de guerras estavam arruinando o país. A companhia tinha o compromisso de alimentar os pobres, realizar trabalhos de assistência espiritual nos lares e cuidar dos doentes nos hospitais, além de reorganizar tais espaços, implementando princípios higiênicos através da individualização dos leitos. De acordo com (CASTRO, 1936) a companhia das Irmãs de Caridade foi fundada para que houvessem mulheres que servissem apenas aos necessitados, por tempo integral, sem outras ocupaçóes relacionadas à vida pessoal, como casamento e família. O treinamento dessas jovens devia ser de poucas palavras, havendo momentos destinados para o exercício da catequese e cuidados domésticos. Os comandos eram dados através de olhares, gestos ou palmas. $\mathrm{O}$ ensino da enfermagem era ministrado pela Superiora às demais irmãs, através de cartas explicativas ou por meio da prática cotidiana umas com as outras. Não havia ainda um manual escrito ou organização técnica, mas a implementação das açóes relacionadas ao cuidado com os enfermos se aproximava do que viria futuramente a ser as "técnicas de enfermagem".

Florence Nightingale é considerada fundadora da Enfermagem moderna, nasceu em 12 de maio de 1820 em Florença, numa família abastada. Estudou diversos idiomas, além de religião, filosofia e matemática, era extremamente religiosa e desde muito cedo apresentava o desejo de ajudar aos pobres e necessitados. Participou como voluntária na Guerra da Crimeia em 1854, quando juntamente com 38 mulheres (irmãs católicas e anglicanas) organizou um hospital com 4.000 mil soldados internos, conseguindo baixar a mortalidade que era de $40 \%$ para $2 \%$. Recebeu um prêmio do governo inglês em virtude desse trabalho e fundou a primeira escola de Enfermagem no Hospital St. Thomas em Londres no ano de 1860. Conheceu o trabalho realizado pelas Irmás de Caridade de São Vicente de Paulo em Paris, no Hôtel-dieu, acompanhando de perto o trabalho administrativo e assistencial que estas realizavam, tendo acesso às regras que norteavam o trabalho das religiosas, o modo como cuidavam dos doentes, aprofundando seus estudos através de anotações, gráficos e listas das atividades desenvolvidas. Em outro momento, retornou ao hospital, permanecendo ali por um mês, vestindo o hábito das Irmás, para sentir o carisma - chamado vocacional para a lida com os necessitados — o convívio com as religiosas no interior do hospital, certamente influenciou a maneira como Nightingale estruturou o seu modelo de Enfermagem (PADILHA, MANCIA, 2005). 
No século XIX Irmãs de Caridade passaram a atuar na administração das Santas Casas em várias partes do Brasil, data de 1852 a vinda das Irmãs de São Vicente de Paula para assumirem os serviços de enfermagem, administrativo e religioso da Santa Casa do Rio de Janeiro, estando estas subordinadas de forma direta ao provedor (PADILHA, 1998).

No final do século XIX as freiras eram responsáveis por inúmeros trabalhos essenciais para a sociedade, principalmente no campo da assistência social, educação e saúde. Com exceção das mulheres pobres, que sempre exerceram diversas funçóes fora do lar para garantir a subsistência da família, as religiosas foram pioneiras no exercício de uma determinada profissão, num tempo em que grande parte das mulheres exercia apenas as funçôes de mãe e dona de casa. A vida religiosa não pode ser, portanto, considerada como marcada apenas por submissão e passividade, ao contrário, essas mulheres eram muitas vezes administradoras de colégios, hospitais, orfanatos e inúmeras obras sociais. Eram elas que determinavam os horários e as regras a serem cumpridas, organizavam a rotina de várias pessoas e resinificavam a condição feminina, numa sociedade patriarcal e machista (NUNES, 1997).

Nesses locais que eram ao mesmo tempo de clausura e liberdade, o princípio fundamental era a separaçáo do mundo. O comportamento das religiosas que viviam a clausura em conventos ou fora deles devia ser distinto do que se observava na sociedade de um modo geral. A vestimenta, a obediência absoluta, a exigência do silêncio durante as refeiçóes, acabavam criando um mundo à parte, esses locais em que as irmãs atuavam eram de trabalho e residência, nos quais as mesmas possuíam o controle rigoroso dos membros e da organização do espaço.

Em 1916 ocorreu uma reuniáo da diretoria da Santa Casa de Cachoeiro sob a direçáo do entáo presidente Felinto Elysio Martins, na qual o mesmo declarou que a finalidade daquela sessão era deliberar sobre a conveniência de encarregar o serviço de enfermeiras do hospital às Irmãs de Caridade. A proposta foi colocada em votação e aprovada por unanimidade, mas não havia congregação, nem religiosas atuando em Cachoeiro, tampouco nos arredores, por isso apesar de aprovada a proposta não se efetivou.

A congregação das Irmãs de Jesus na Santíssima Eucaristia, foi fundada em Cachoeiro no ano de 1927 por madre Gertrudes de São José. A religiosa inaugurou um colégio, à princípio, com a finalidade de escolarizar as moças da regiáo. Atento ao trabalho das religiosas junto à comunidade do município, o então presidente da Santa Casa na época, Mário Rezende, escreveu uma carta à madre pedindo a atuaçáo das religiosas junto aos enfermos do hospital, atendendo ao pedido feito, a Superiora designou algumas freiras da irmandade para atuarem na Santa Casa de Cachoeiro.

$\mathrm{O}$ período em que estas passam a administrar o hospital — início do século XX coincide com diversas mudanças em relação ao discurso e assistência médica no país, portanto se faz necessário destacar os acontecimentos que contribuíram para que tais transformaçóes ocorressem. 


\section{O DISCURSO HIGIENISTA NA IMPRENSA DE CACHOEIRO}

A partir da década de 1920 o discurso médico acerca da saúde e da doença começou a se transformar, principalmente por causa das reformas sanitárias propostas por Carlos chagas e pela atuaçáo da Liga Pró-Saneamento. O discurso de Miguel Pereira que caracterizava o Brasil como um imenso hospital foi inspirado no relatório da expediçáo científica de 1912 chefiada por Belisário Penna e Arthur Neiva, que percorreu o norte da Bahia, sudoeste de Pernambuco, sul do Pará e todo o estado de Goiás. O relatório desses dois médicos tornou-se instrumento fundamental para a realização de um diagnóstico do Brasil, favorecendo o surgimento de políticas públicas de combate a epidemias que aniquilavam o povo brasileiro, além de propostas de saneamento dos espaços públicos e da introdução de novos hábitos, capazes de diminuir ou erradicar moléstias diversas. Esse novo discurso - denominado de higienista — náo ficou restrito apenas aos meios acadêmicos, passou a ser tema frequente nas Rodas de conversa com os amigos, mesas de bares, nos artigos publicados nos periódicos em circulação, enfim, era tema presente no dia a dia dos brasileiros. Essas mudanças repercutiram no cotidiano dos moradores de Cachoeiro de Itapemirim, sendo nitidamente percebidas através das notícias veiculadas no jornal $\mathrm{O}$ Cachoeirano - importante periódico fundado no ano de 1887 - que passou a publicar no dia 30 de março de 1922 uma coluna intitulada: Pela Medicina, assinada pelo médico Luiz Lindenberg. Nessa primeira abordagem o médico afirmava que forneceria consultas a todos os leitores do jornal, por meio de cartas ou pessoalmente em seu consultório. $\mathrm{Na}$ mesma página o colunista escreveu um artigo sobre febres climáticas, no qual abordava a causa das febres intestinais, denominadas por ele como Paratyphicas. No dia 06 de abril iniciou as respostas às cartas, nas quais identificava os leitores pelas iniciais de seus nomes, explicando a possível moléstia, formas de tratamento e ainda recomendando a alguns que o procurem em seu consultório — anexo a farmácia Guandu — para maiores esclarecimentos. Em anuncio publicitário veiculado no jornal o médico Luiz Lindenberg informava os horários de consulta, destacando que em seu laboratório médico realizava exames de sangue, urina, pus e escarros para diagnóstico.

No dia 27 de abril de 1922 foi publicado no O Cachoeirano um artigo com o título: "Cuidado com a água", advertindo a população para que consumisse apenas água potável, como forma de evitar infecçóes e doenças como: febre tifoide e cólera. Em 11 de maio de 1922 a sessão: "Pela Medicina", assinada pelo Dr. Luiz Lindenberg trouxe a seguinte advertência:

Este artigo e outros que se seguirão, sem preocupação de estylo e de linguagem technica, são dirigidos não aos technicos, mas ao povo em geral, ensinando-lhes meios e modos, ao seu alcance, para se livrar ou se curar das moléstias mais comuns, em nosso meio ( $O$ Cachoeirano, 1922).

E começa abordando o Impaludismo, o tema não se esgotava em uma única edição, sendo necessários vários dias para conclusão da temática proposta, e início de outra de interesse da população.

As modernas profilaxias implementadas pelo poder público em prol da coletividade provocaram profundas mudanças na sociedade, favorecendo o surgimento de uma nova 
compreensão acerca da doença e da saúde. Foi realizada uma intensa pesquisa no jornal Correio do Sul entre junho de 1928 e junho de 1929 na qual constatou-se que diariamente eram feitos anúncios de farmácias que além de oferecerem "todo sortimento de drogas", forneciam consultas médicas com profissionais que atuavam no município. Passaram a ser anunciados com frequência diária o Elixir de Nogueira, para combater inflamaçóes do útero, dores no peito, corrimento nos ouvidos, manchas na pele e tremores nos ossos; Ankylol para combate à opilação, também descrito como amarelão; Cafiaspirina no combate à cólicas e demais incômodos do período menstrual; Biotônico Fontoura, fortificante indicado para homens, senhoras e crianças, além do suplemento alimentar Quaker Oats, que tinha como finalidade aumentar a disposição para o trabalho, fazendo com que o indivíduo passasse a sentir-se mais "energético", sendo indicado para crianças, adultos, convalescentes e "intellectuantes".

Havia no periódico uma sessão intitulada: O que as Mães Precisam Saber, na qual eram enviadas cartas de mulheres que tinham alguma dúvida acerca de determinadas doenças. As cartas eram respondidas por um médico, que geralmente tranquilizava as mães e fornecia esclarecimentos sobre o tema. Destacamos aqui o relato de uma mulher que afirmava estar muito preocupada pois seu filho se encontrava com diarreia em "virtude de dentição", destacando que o motivo de sua preocupação consistia no fato de uma criança da vizinhança ter tido convulsóes por causa de situaçáo similar.

Outra sessão que merece destaque é o folhetim: O Médico de si mesmo, no qual o Dr. Luís Phillipe escrevia sobre várias doenças, como: gastrite aguda, doenças do coração, hipertensão, entre outras, destacando detalhadamente os sintomas, bem como a forma de tratamento. $\mathrm{O}$ informativo nunca se esgotava num único dia, trazia sempre no final da página a legenda: continua, sem, contudo, indicar em que data, incentivando o leitor a comprar o jornal diariamente caso quisesse ler a continuação do folhetim. No dia 11 de abril de 1929 foi publicado um informe destacando que o prefeito Francisco Alves Athayde determinou vistoria nos quintais, chácaras e logradouros, tal fato se deu em virtude da descoberta de um caso de febre amarela em Campos, enfatizando que por haver comunicação diária de pessoas da cidade de Campos com habitantes de Cachoeiro a medida se fazia necessária. O edil convocou toda a população para que colocasse o lixo retirado das habitaçóes junto às calçadas para que fosse recolhido. Nos dias 06 e 20 de abril foram publicados informativos do médico Luís Phillipe com o título: "O que todos devem saber sobre a Febre Amarella”, demonstrando que havia uma preocupação em relação à incidência de casos na região.

A assistência filantrópica sempre ocorreu ao longo da história da humanidade, sendo o socorro aos pobres e desvalidos muitas vezes financiado por beneméritos, irmandades e associações de diversos modelos. Em Cachoeiro de Itapemirim a Santa Casa de Misericórdia recebia com frequência donativos em dinheiro e gêneros diversos, que eram utilizados para manter o hospital funcionando. O que geralmente ocorria, como o noticiado no dia 05 de março de 1929, é que eram divulgados o nome dos beneméritos e a quantia doada em dinheiro, o mesmo ocorria com os que doavam gêneros como: arroz, feijão, batata, coelho e material de higiene e limpeza. Além de ser uma forma de reconhecimento 
público, a notícia de que aquelas pessoas eram colaboradoras de obra social táo nobre, servia muitas vezes como trampolim político ou meio de conseguir inserção na "grande sociedade" do município.

\section{ENTRE 0 CUIDAR E 0 CURAR: AS RELIGIOSAS NA SANTA CASA DE MISERICÓRDIA}

É nesse contexto de profundas transformaçóes em relação ao discurso médico e o tratamento de moléstias diversas, que as Irmãs de Jesus na Santíssima Eucaristia passam a administrar a Santa Casa de Cachoeiro de Itapemirim. Esse período foi marcado pela incidência de doenças graves que dizimaram um grande contingente populacional na região, entre essas enfermidades pode-se citar a tuberculose, febre amarela e febre tifoide.

No dia 07 de maio de 1929 foi publicado uma nota no jornal Correio do Sul sobre a entrega da direção de todos os serviços internos da Santa Casa aos cuidados das religiosas, sendo a Superintendência Geral dos Serviços sob a responsabilidade da Madre Gertrudes de São José. Após dois dias o periódico publicou o contrato de serviço firmado entre a Madre e o Hospital. A seguir citaremos alguns trechos desse contrato que tem nove cláusulas:

1. a A Irmã Gertrudes de São José, diretora do Colégio Sagrado Coração de Jesus, também designada primeira contratante, contrata com a Santa Casa de Misericórdia de Cachoeiro de Itapemirim, também designada contratante ou simplesmente Santa Casa, representada por seu presidente Mário Resende e devidamente autorizada por Assembleia Geral, a direção interna de todos os serviços, sem despesa alguma para a primeira contratante e sob as condiçóes seguintes:

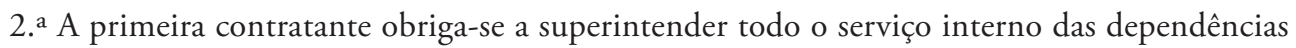
da Santa Casa, inspecionando-os diariamente sob força maior e zelando para sua economia, limpeza, asseio, ordem e moralidade. Conforme dispóe o regulamento interno;

[...] 7. ${ }^{\text {a }}$ A segunda contratante obriga-se a dar às Irmâs uma alimentação boa, sadia [...] bem como no caso de doenças de qualquer delas, dar-lhes também além dos necessários medicamentos, a respectiva assistência médica e, verificando algum falecimento, serão por conta da Santa Casa todas as despesas de transporte e enterro;

8. a A segunda contratante pagará a cada uma das Irmãs empregadas nos serviços da Santa Casa, inclusive à primeira contratante a importância mensal de $100 \$ 000$ (cem mil réis) e dará também mais $150 \$ 000$ (cento e cinquenta mil réis) mensalmente para serem aplicados nos seus serviços religiosos podendo a primeira contratante contratar capeláo com as atribuiçôes que achar pertinente;

9. ${ }^{\text {a }}$ Este contrato terá vigor durante quatro anos a partir da data de sua assinatura e, se não for proposta a sua rescisão, será ele renovado por mais quatro anos e assim sucessivamente (Correio do Sul, 9 de maio de 1929).

Conforme determina o contrato, as religiosas eram responsáveis por supervisionar todos os setores do hospital, como: lavanderia, rouparia, centro cirúrgico, maternidade, cozinha, farmácia, além de assistência espiritual aos enfermos e seus familiares. Recebiam para a realização desses serviços, um salário coletivo, que era entregue à Superiora da Congregaçáo para serem aplicados nas demais obras assistenciais realizadas pela irmandade. 
Havia no hospital uma diretoria eleita, formada por membros da sociedade local e a diretoria "interna", na qual as irmãs atuavam, a estas cabia supervisionar todos os setores do hospital, cuidando para que este funcionasse adequadamente, caso encontrassem alguma irregularidade, deveriam levar ao conhecimento do presidente da instituição para que o mesmo tomasse as providências cabíveis.

Ao contrário da diretoria eleita, que tinha horário fixo de trabalho, as irmás permaneciam no hospital — por residir nas dependências do mesmo — por isso em qualquer emergência elas acionavam os médicos e demais membros da diretoria. Os pacientes se identificavam muito com as freiras e relatavam suas angústias, temores e até se queixavam caso entendessem que estavam sendo vítimas de maus-tratos ou descaso por parte da equipe médica. Nesse sentido o papel destas era fundamental, pois se o médico quisesse continuar atuando na instituiçáo precisava de certa forma do aval das religiosas, se houvessem malsinaçóes relacionadas a sua prática junto aos doentes, elas denunciavam junto à diretoria, o que podia provocar a demissão do profissional.

Até a primeira metade do século passado as mulheres tinham muito pudor de se consultarem e de realizarem seus partos com médicos, o mais usual é que partejassem no conforto do seu lar sob os cuidados de uma parteira. Mas a partir da inserçáo das irmás no quadro de funcionários da Santa Casa, as mulheres passaram a buscar com maior frequência os serviços do hospital, bem como a buscar atendimento para seus filhos, sempre que necessário.

Irmã Celina que ingressou na congregação com 24 anos e passou a atuar na Santa Casa no ano de 1935, recebeu destaque, por ter um pequeno quarto ao lado da maternidade - a religiosa era acionada a qualquer hora do dia ou da noite para a realizaçáo dos partos - e quando tinha algum tempo livre, costurava roupas para bebês, cintas e camisolas para as mães pobres, geralmente chamadas de indigentes. Ela trabalhou no hospital por cerca de 52 anos — de 1935 a 1987, quando faleceu — calcula-se que tenha realizado cerca de dez mil partos (MOULIN, 2011).

Numa época em que o Brasil era considerado um imenso hospital, não causa surpresa afirmar que as irmãs, independente do contato direto com os enfermos, fossem acometidas por doenças graves que assolavam a região do sul do Estado do Espírito Santo nesse período. Em carta datada de 22 de julho de 1938 a madre Gertrudes de São José pediu que as demais religiosas continuassem rezando pela Irmã Edwirges que estava há um mês doente de pariotifo. ${ }^{6}$

Em 15 de dezembro de 1938 a Superiora informou — através de correspondência - que irmã Olívia havia se submetido a uma operação de apendicite e que passa bem, mas em outra carta datada de 31 de dezembro de 1938, a mesma relatou com pesar o falecimento da referida irmã, que após a cirurgia foi atacada por uma febre muito alta, com o passar dos meses foram conhecidos os sintomas da febre tifóide e como destacou a madre, a medicina esgotou todos os seus

6 Infecção intestinal bacteriana, também conhecida por febre paratifoide, causada pela ingestão de alimentos ou água contaminada pela bactéria salmonela paratyphi. 
recursos sem nenhum resultado. $\mathrm{Na}$ carta, a superiora da congregação narra de forma "quase poética" o velório:

Houve três missas de corpo presente. O seu coche fúnebre todo coberto de lírios onde repousava o seu corpo virginal foi acompanhado por inúmeras pessoas que confundiam as suas lágrimas com as nossas. As ruas estavam repletas de pessoas que vinham apreciar aquele quadro triste, mas belo (Cartas de Madre Gertrudes de São José, 1938, p. 108).

De acordo com a descrição do velório percebemos que à época a morte era "um espetáculo", capaz de fazer refletir sobre a fugacidade da vida, de gerar comoção e solidariedade entre estranhos, espetáculo capaz de minimizar as mazelas cotidianas.

A madre se preocupava com a saúde e bem-estar das freiras, mas também com a atuação profissional das religiosas que trabalhavam na Santa Casa. Em carta de 10 de agosto de 1939 a mesma alertava às irmás para que se lembrassem do capítulo nono das Constituiçóes do Regimento que determinava a proibição das mesmas de terem correspondência com qualquer que seja, sem licença de sua superiora, nem amizades particulares com pessoas religiosas, mesmo confessores e diretores. Destacando que era proibido às religiosas dar ou receber presentes, entreter-se com conversas fiadas com qualquer secular, isto é, médicos, enfermeiros, empregados e até com sacerdotes fora do confessionário. $\mathrm{Na}$ mesma carta madre Gertrudes alertava sobre a importância da obediência à determinação da Saúde Pública, "que ordenou a todas as pessoas que tratavam com doentes, seja nas enfermarias, salas de operaçóes e curativos, a vestirem-se de branco", segue escrevendo que em todos os hospitais onde havia atuação de membros da irmandade, as religiosas deveriam usar um avental inteiro com mangas compridas e véu branco.

Podemos observar que as mudanças no pressuposto do cuidar para o curar chegaram ao município em fins de1930, alterando de certa forma a rotina do hospital e o modo de atuação das irmãs junto aos doentes. Analisando os escritos da madre, constatamos que houve resistência por parte das religiosas em acatar a nova vestimenta. Tanto que em carta do dia 10 de agosto de 1939 a Superiora se queixa que algumas freiras não estão cumprindo as exigências da Saúde Pública, tampouco as suas determinaçóes, destaca que as diretoras deveriam ser as primeiras a cumprir a norma para dar o exemplo, mas recusavam-se a e segue afirmando que para evitar escândalos, proibiria a renovação dos votos às irmãs que antes da data fixada não estiverem vestidas conforme o que foi determinado.

As irmãs que atuavam na Santa Casa de Cachoeiro passaram a buscar capacitaçóes através de cursos de enfermagem, como forma de adequação aos novos rumos da saúde no país. No ano de 1946 - dia 08 de março, madre Gertrudes escreveu às irmás Olívia e Celestina sobre a importância de ambas fazerem o curso de enfermagem superior na renomada escola Ana Nery no Rio de Janeiro, para obtenção de certificado, destacando que o estudo e a prática adquirida na escola possuíam muito valor nos hospitais. Irmã Olívia foi a pioneira, fazendo inclusive especialização em Sáo Paulo, ao regressar passou a ministrar cursos de "auxiliar de enfermagem" com emissão de certificados, depois dela um número significativo de religiosas ingressou na escola de enfermagem no Rio de Janeiro. Antes disso o que havia era a aprendizagem na prática, adquirida no dia a dia da instituiçáo. 
As cartas escritas pela Superiora eram lidas em todas as congregaçóes em que as religiosas da irmandade atuavam, como forma de alertar, corrigir, informar e encorajar as demais. Em 02 de maio de 1937 a madre escreveu uma Carta Circular endereçada as "queridas filhas" da Santa Casa de Misericórdia, na qual elogiava o trabalho das religiosas, destacando que "haviam dissabores, contrariedades, desgostos e perseguiçóes, promovidas por pessoas a quem estas dedicavam os mais ternos carinhos”. Apesar de não ser objetiva em relação ao significado dessas perseguiçôes, a hipótese que aqui defendemos é de que haviam conflitos internos no interior do Hospital, em virtude das mudanças que ocorriam na implementação do novo modelo de saúde coletiva. Para reforçar tal argumento analisamos uma carta datada de 20 de agosto de 1951 — época em que as irmãs apesar de continuarem atuando na instituição, não administravam mais o Hospital — na qual a madre busca informaçóes detalhadas sobre o cumprimento das obrigaçóes por parte das religiosas, inquirindo a estas se estavam mantendo uma postura séria no trato com os médicos e empregados; se guardavam postura religiosa junto aos seculares; se a nova administração as tratava com respeito e consideração. Na correspondência madre Gertrudes segue elencando os deveres de uma diretora hospitaleira que seriam os seguintes: visitar os doentes diariamente, tanto pensionistas como indigentes, atendendo-os em suas reclamaçóes, para que náo as fizessem aos diretores; confortá-los; aconselhá-los nos Sacramentos para que ninguém morresse sem eles; percorrer os empregos das irmãs para verificar se cumpriam suas obrigaçōes ou se se deixavam em falta "os doentinhos". Solicitava ainda que tratassem bem umas às outras, os seculares e sobretudo os membros da diretoria.

De acordo com a irmá Aurora Côgo, ${ }^{7}$ a partir da década de 1950 as freiras deixaram a administração interna do hospital e passaram a atuar unicamente como funcionárias da instituição, trabalhando apenas em alguns setores. Um fato que colaborou sobremaneira para a saída das religiosas da administração foram as queixas que alguns funcionários faziam de que as irmãs possuíam privilégios dentro da instituição, pois além de residirem nas dependências da mesma, alimentavam-se da comida que era produzida no nosocômio - hospital - e utilizavam os serviços da lavanderia, enquanto os demais empregados não gozavam de tais benefícios.

Mas para além de possíveis perseguições internas, percebemos as intensas transformaçóes na sociedade que consequentemente afetavam a dinâmica do hospital. A demanda por atendimento aumentou significativamente o que acarretou a expansão do quadro de funcionários. Nesse período passaram a atuar na instituição enfermeiras e enfermeiros com formação técnica, seus valores e vivências iam de encontro aos ideais religiosos das irmãs que eram proibidas de manter amizades com seculares, ou seja, freiras e demais funcionários da instituição apesar de conviverem no mesmo espaço físico, viviam em "mundos diferentes". As irmãs enfermeiras eram acima de tudo, freiras, essa era a sua real

7 Membro da congregação desde a década de 1960. É responsável por preservar a história da irmandade. Em 10 de julho de 2017 aceitou conversar nas dependências do Colégio católico Jesus Cristo Rei — fundado em 1927 e desde a época dirigido pelas irmãs — na cidade de Cachoeiro de Itapemirim, com a autora deste artigo a respeito da congregação e sobre a atuação das religiosas na Santa Casa, relatando alguns fatos que favoreceram a elaboração desta pesquisa. 
profissão e ideal de vida, a partir do momento em que as atribuiçôes referentes a atuação no hospital entram em conflito com o chamado espiritual, as mesmas náo hesitarão em partir para outras frentes de trabalho.

\section{CONCLUSÃO}

As religiosas da congregação de Jesus na Santíssima Eucaristia passaram a atuar na Santa Casa de Misericórdia de Cachoeiro de Itapemirim em 1929, assumindo a administração interna do hospital. A presença das freiras na instituição concedeu à mesma uma certa "credibilidade", fazendo com que muitas pessoas, - especialmente as mulheres - passassem a utilizar os serviços do nosocômio sempre que necessário, abstendo-se de forma gradativa dos serviços de curandeiros, parteiras e práticos.

A exigência de habilitação específica para o exercício de diversas profissões, ecoaram no município fazendo com que as religiosas buscassem se adequar às novas normas da Inspetoria de Saúde, seja através da vestimenta ou de qualificação em cursos de enfermagem e especialização. Tais mudanças, aliadas a um novo contexto social marcado por novos valores geraram certo conflito entre o fazer das irmãs enfermeiras e a vocação religiosa das mesmas, tanto que na década de 1950 estas deixam a administração interna do hospital e aos poucos migram para outras frentes de atuação junto aos necessitados. 


\section{REFERÊNCIAS}

\section{DOCUMENTAÇÃO PRIMÁRIA}

O Cachoeirano, 1900 e 1901. Biblioteca nacional - hemeroteca digital.

Correio do Sul, ano 1, jun. 1928 a junho de 1929 (versão microfilmada). Arquivo Público do estado do Espírito Santo.

LIVROS DE ATAS, (1900-1951). Santa Casa de Misericórdia. Cachoeiro de Itapemirim.

LIVRO DE "IMPRESSÓES" - Relatos de Visitantes (1929-1949). Santa Casa de Misericórdia. Cachoeiro de Itapemirim.

SÃO JOSÉ, Gertrudes de (madre). Cartas. Congregação das irmãs de Jesus na eucaristia (maio de 1937 a junho de 1962). Belo Horizonte: São Vicente, 1981.

\section{OBRAS DE APOIO}

ABREU, Laurinda. O papel das Misericórdias dos lugares além-mar na formação do império português. História, Ciências, Saúde, Rio de Janeiro, v. 8, n. 3, pp. 591-611, set.-dez. 2001.

ANCHIETA, José de. Cartas, Informaçóes, Fragmentos Históricos e Sermóes do Padre José de Anchieta (1554-1594). Rio deJaneiro: Civilização Brasileira 1933.

BYNUM, William. História da medicina. Porto Alegre: L\&PM Pocket, 2011.

CALMON, Pedro. História do Brasil (séc. XVI). Rio de Janeiro: Livraria José Olympio, 1971. v. 1

FRANCO, Renato. Pobreza e caridade leiga: as Santas Casas de Misericórdia na América Portuguesa. 2011, INFORMAR NÚMERO DE FOLHAS. Tese. (Doutorado. em... INFORMAR) INFORMAR FACULDADE, Universidade de São Paulo (USP), São Paulo, 2011.

FOUCAULT, Michel. Vigiar e punir. Petrópolis (RJ): Vozes, 1987.

GEREMEK, Bronislaw. A piedade e a forca: história da miséria e da caridade na Europa. Lisboa: Terramar, 1986.

MOULIN, Ariette. Santa Casa de Misericórdia de Cachoeiro de Itapemirim, 19002010. Cachoeiro de Itapemirim, Gracal, 2011.

NUNES, Maria José Rosado. Freiras no Brasil. In: DEL PRIORE, Mary (Org.). História das mulheres no Brasil. São Paulo: Contexto, 1997.

PADILHA, M. I. C. S. As Representaçóes da História da Enfermagem na prática cotidiana atual. Revista Brasileira de Enfermagem, Brasília, v. 52, n. 3, p. 443 - 454, julho/setembro, 1999.

; MANCIA, J. R. Florence Nigthingale e as irmãs de caridade: revisitando a história. , v. 58, n. 6 , pp. $723-6,2005$. 
PADILHA, M. I. C. S. A mística do silêncio: a enfermagem na Santa Casa de Misericórdia do Rio de Janeiro no século XIX. Pelotas (RS): Universitária/UFPel, 1998.

SÁ, Isabel dos Guimarães; PAIVA, José Pedro. Introdução. In: PAIVA, José Pedro (Coord.). A fundaçáo das Misericórdias: o reinado de D. Manuel I. Lisboa: Centro de Estudos de História Religiosa, 2004, pp. 7-26. v. 3.

WOOD - Russel, A. J. R. Fidalgos e filantropos: a Santa Casa da Misericórdia da Bahia (1550-1755). Brasília: EdUnB,1981.

STEPAN, N. Gênese e evoluçáo da ciência brasileira: Oswaldo Cruz e a política de investigaçáo científica e médica. Rio de Janeiro. Artenova, 1976.

Arquivo recebido em 31/10/2017

Arquivo aprovado em 20/12/2017 